SFU Education Review

Martin, October 2013

\title{
Learning Together 2013 Keynote Randall Martin
}

Randall Martin gave the 2013 Learning Together Conference Keynote. The video of the keynote speech is located on Vimeo via the following link: http://vimweo.com/80399270

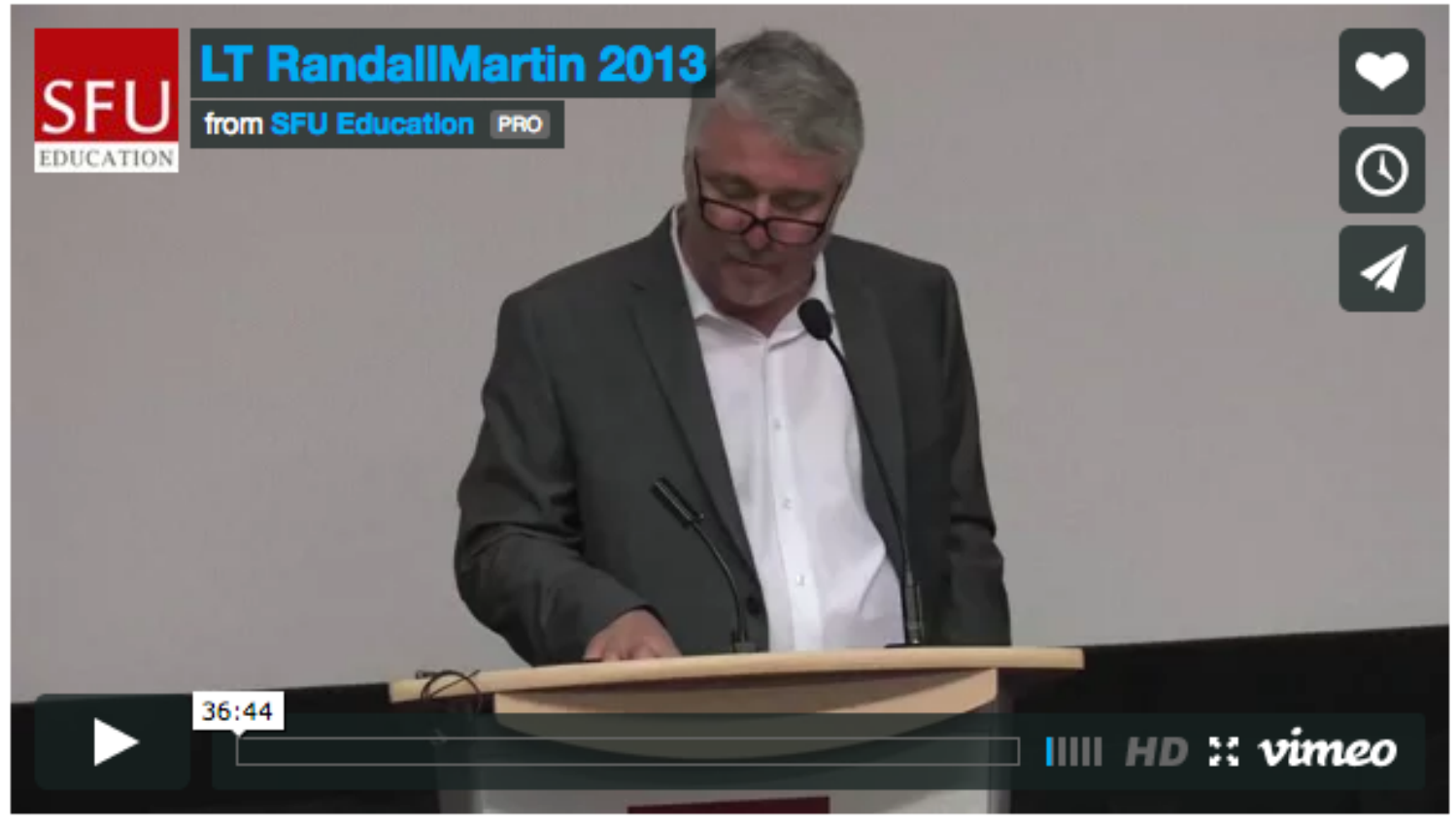

